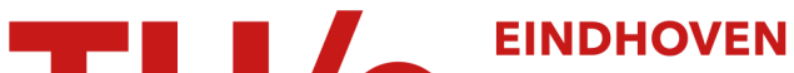 \\ UNIVERSITY OF \\ TECHNOLOGY
}

\section{Power handling limit of liquid lithium divertor targets}

\section{Citation for published version (APA):}

Rindt, P., Morgan, T. W., Jaworski, M. A., \& Lopes Cardozo, N. J. (2018). Power handling limit of liquid lithium divertor targets. Nuclear Fusion, 58(10), [104002]. https://doi.org/10.1088/1741-4326/aad290

\section{Document license:}

TAVERNE

DOI:

10.1088/1741-4326/aad290

Document status and date:

Published: 01/10/2018

\section{Document Version:}

Publisher's PDF, also known as Version of Record (includes final page, issue and volume numbers)

\section{Please check the document version of this publication:}

- A submitted manuscript is the version of the article upon submission and before peer-review. There can be important differences between the submitted version and the official published version of record. People interested in the research are advised to contact the author for the final version of the publication, or visit the $\mathrm{DOI}$ to the publisher's website.

- The final author version and the galley proof are versions of the publication after peer review.

- The final published version features the final layout of the paper including the volume, issue and page numbers.

Link to publication

\section{General rights}

Copyright and moral rights for the publications made accessible in the public portal are retained by the authors and/or other copyright owners and it is a condition of accessing publications that users recognise and abide by the legal requirements associated with these rights.

- Users may download and print one copy of any publication from the public portal for the purpose of private study or research.

- You may not further distribute the material or use it for any profit-making activity or commercial gain

- You may freely distribute the URL identifying the publication in the public portal.

If the publication is distributed under the terms of Article 25fa of the Dutch Copyright Act, indicated by the "Taverne" license above, please follow below link for the End User Agreement:

www.tue.nl/taverne

Take down policy

If you believe that this document breaches copyright please contact us at:

openaccess@tue.nl

providing details and we will investigate your claim. 


\section{(⿶) nuclear

LETTER

Power handling limit of liquid lithium divertor targets

To cite this article: P. Rindt et al 2018 Nucl. Fusion 58104002

View the article online for updates and enhancements.

\section{Related content} Present status of liquid metal research for
a fusion reactor

Francisco L Tabarés

Liquid metals as a divertor plasma-facing material explored using the Pilot-PSI and Magnum-PSI linear devices

T W Morgan, P Rindt, G G van Eden et al.

Liquid-metal plasma-facing component research on the National Spherical Torus Experiment

M A Jaworski, A Khodak and R Kaita 


\title{
Letter
}

\section{Power handling limit of liquid lithium divertor targets}

\author{
P. Rindt ${ }^{1} \oplus$, T.W. Morgan $^{2}{ }^{\oplus}$, M.A. Jaworski $^{3}$ and N.J. Lopes Cardozo ${ }^{1}$ \\ ${ }^{1}$ Eindhoven University of Technology, Science and Technology of Nuclear Fusion Group, \\ Eindhoven, Netherlands \\ 2 DIFFER-Dutch Institute For Fundamental Energy Research, De Zaale 20, 5612AJ Eindhoven, \\ Netherlands \\ ${ }^{3}$ Princeton Plasma Physics Laboratory, Princeton, NJ, United States of America \\ E-mail: p.rindt@tue.nl
}

Received 9 May 2018, revised 20 June 2018

Accepted for publication 11 July 2018

Published 31 July 2018

\begin{abstract}
A model is formulated to make a first estimate of the maximum tolerable power of liquid lithium $(\mathrm{Li})$ divertor targets, and to gain insight into their behaviour in terms of Li loss rate and surface temperature. The model, formulated as a simple analytical expression, states that the incoming power is balanced by heat conduction through the target and by the Li which dissipates energy via evaporation, radiation and ion-neutral friction. A target is considered to fail when the net Li loss flux from the surface exceeds the available supply. The model is evaluated over a range of input parameters: Li supply rate, surface layer thickness, redeposition coefficient, and dissipated energy per Li particle lost to the plasma. Based on the results, first, surface temperature locking is expected above a deposited power of $\sim 10 \mathrm{MW} \mathrm{m}^{-2}$. Second, Li targets are expected to be extremely robust against power deposited during short transient events. A surface layer thickness of 50 micron is sufficient to withstand $60 \mathrm{MJ} \mathrm{m}^{-2}$ vertical displacement events or $20 \mathrm{MJ} \mathrm{m}^{-2}$ disruptions.
\end{abstract}

Keywords: fusion, divertor, lithium, power handling, design

(Some figures may appear in colour only in the online journal)

\section{Introduction}

Liquid metal (LM) divertor solutions have often been proposed [1-5] as they potentially address issues with existing solid tungsten (W) divertors. Important arguments for this claim are: first, the lifetime of a solid $\mathrm{W}$ divertor is limited by erosion [6], whereas a liquid metal target can be replenished [3]. Second, liquid lithium (LL) specifically can retain up to $100 \%$ of incoming hydrogen [7], which could lead to significantly improved plasma performance as experimentally observed with LL in NSTX and CDX-U [8, 9]. The downside is that, unless retention can be prevented, fast circulation and filtering of lithium ( $\mathrm{Li}$ ) will be unavoidable to meet tritium inventory requirements, or high temperature regimes as considered in this work have to be used to prevent retention [10]. Third, the topic of this letter, in the case of the monoblock divertor design for ITER the power handling limit is only just above the operating point. Recent work shows melting of the monoblock edges is most likely unavoidable and that the safety margin for heat load control is extremely small [11]. Better power handling is expected for LM targets due to so called 'vapor shielding' $[3,12,13]$. This phenomenon has long been studied for solid materials (e.g. the 'virtual limiter' in [14] or more recently [15]); though, only the LM the effect can be used without permanently damaging the divertor. However, the exact power handling limit has not yet been found. All these issues are critical factors for the feasibility of commercial fusion plants. 
In this work, a model is formulated to gain insight into the behavior of LL targets in terms of Li loss rate and surface temperature, and to make a first estimate of the maximum tolerable power, beyond which components will be damaged. The model is based on theory discussed in section 2. The model itself is presented in section 3 and considers a generalized target design, which is regarded to fail when the $\mathrm{Li}$ on the plasma facing surface (PFS) is depleted. Discussion and conclusion follow in sections 4 and 5 respectively.

\section{Theory}

Li that is removed from the PFS dissipates energy in the plasma. This is an important contribution to the power handling capabilities of LL components. The work presented in [16], provides us with the energy dissipated per Li particle in the plasma, $\epsilon_{\text {cool }}$. This parameter is sensitive to the particle residence time in the plasma, $\tau$, the electron density, $n_{\mathrm{e}}$, and most importantly $T_{\mathrm{e}}$.

The electron temperature can vary strongly throughout the plasma. Close to the divertor in detached scenarios $T_{\mathrm{e}}$ is in the range of $1-10 \mathrm{eV}[17,18]$, which puts $\epsilon_{\text {cool }}$ in the order of $5-10 \mathrm{eV}$. Whereas around the midplane in the SOL, $T_{\mathrm{e}}$ is expected to be in the order of a few hundreds of $\mathrm{eV}$ [16], and also during transients events such as ELMs, $T_{\mathrm{e}}$ can exceed $100 \mathrm{eV}$ as measured and modeled for JET [19]. Correspondingly, $\epsilon_{\text {cool }}$ could be optimistically estimated as $300 \mathrm{eV}$. The present work considers $\epsilon_{\text {cool }}$ of 5,50 , and $500 \mathrm{eV}$. Though the latter is an overestimate, it is chosen to be consistent with a logarithmic scale.

Lastly, we must consider redeposition. A large fraction of the lost $\mathrm{Li}$ is expected to be ionized within the sheath region [20], and will be promptly redeposited. On top of that, Li that is not promptly redeposited and escapes the sheath region can still be redeposited due to, e.g., momentum exchange with the incoming plasma flux. In [21] it is suggested that the total redeposition fraction $R$ in fusion relevant conditions is $>0.99$. Though, below $T_{\mathrm{e}}<1 \mathrm{eV}$ this could drop even to $R<0.1$. One can imagine that in the case of prompt redeposition there is no time for the collisional radiative process that results in $\epsilon_{\text {cool }}$ to be dissipated. While not all redeposition is prompt redeposition, for practical purposes this letter will assume that all redeposited particles are indeed promptly redeposited, and therefore $\epsilon_{\text {cool }}$ will only be dissipated by the permanently lost particles which are described by the net loss rate $\Gamma_{\text {net }}$. Effectively, this is a worst-case assumption.

\section{Power handling model}

A generalized divertor target is considered which consists of a W substrate which is cooled on the back side. To allow comparison to the ITER monoblocks the temperature of the coolant and the effective thermal conductance of the complete target are taken $T_{\text {cool }}=120^{\circ} \mathrm{C}$ and $C=13 \cdot 10^{3} \mathrm{~W} \mathrm{~m}^{-2}$ $\mathrm{K}^{-1}$, as derived from [22]. On the $\mathrm{W}$ sits a $\mathrm{Li}$ layer the thermal resistance of which is neglected due to its low thickness.
Convective heat transport due to e.g. flow induced by thermoelectric currents is also neglected [23]. Furthermore, it is assumed there is no additional contact resistance when good wetting is achieved.

The layer has a surface number density of $N$ particles $\mathrm{m}^{-2}$, which is constantly re-supplied by a uniform steady state (SS)

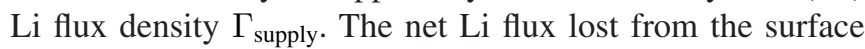
to the plasma is described as Langmuir evaporation corrected for redeposition $\Gamma_{\text {net }}=\Gamma_{\text {vap }}(1-R)$, and is constrained by the available supply, $\Gamma_{\text {net }} \leqslant \Gamma_{\text {supply }}+N / t$. Here, $t$ is the pulse length. The target is considered to fail when either the $\mathrm{Li}$ on the PFS is depleted, or the melting point of the W substrate is reached. Also, only temperatures are allowed where retention is reduced (as measured in [10]). A conservative estimate of the minimum temperature is taken to be $700 \mathrm{~K}$.

The target is described by an energy balance in which the incoming power flux from the plasma must be balanced by (1) power dissipation via thermal conduction and (2) power dissipation by Li entering the plasma. Contributing to the second term are $\epsilon_{\mathrm{cool}}$, and the evaporation energy $E_{\mathrm{vap}}=1.41 \mathrm{eV}$.

$$
Q_{\text {plasma }}=Q_{\text {cond }}+\Gamma_{\text {vap }}(1-R)\left(\epsilon_{\text {cool }}+E_{\text {vap }}\right) .
$$

Here, $\Gamma_{\text {vap }}$ is a strong function of $T_{\text {surf }}$, and $Q_{\text {cond }}$ represents the conducted power density. The latter is composed of a term describing transient heat transfer, taken from [24], and a term for steady state heat transfer.

$$
\begin{aligned}
Q_{\text {cond }}= & \left(T_{\text {surf }}-T_{\text {surf }}^{\infty}\right) t_{\text {pulse }}^{-0.5} \sqrt{\pi C_{p} \rho k} / 2 \\
& +C\left(T_{\text {surf }}^{\infty}-T_{\text {cool }}\right) .
\end{aligned}
$$

Equation (1) is solved for $T_{\text {surf }}$ as both the conducted power and $\mathrm{Li}$ evaporation rate are dependent on it. $C_{p}, \rho$ and $k$ are the heat capacity, density, and thermal conductivity of the substrate respectively. Temperature $T_{\text {surf }}^{\infty}$ is the steady state surface temperature, which is obtained by solving the power balance for $t=\infty$.

A typical result is shown in figure 1. The red line is calculated considering only conductive dissipation, and represents the ITER monoblocks. The blue line indicates the behavior of a Li target: similar to the monoblocks there is a steady state regime, where the tolerable power is set mainly by $\Gamma_{\text {supply. }}$. The pulsed regime has a slope of -1 also because it is set by the available $\mathrm{Li}$, but this time the amount of $\mathrm{Li}$ available on the surface during a pulse, $N / t$, is the dominant contribution. Naturally, the Li in the surface layer corresponds to a fixed energy density that can be dissipated, thus resulting the -1 slope. For very short pulses the tolerable power density is again limited by the substrate surface temperature, which exceeds the $\mathrm{W}$ melting temperature before it is sufficient to evaporate all available $\mathrm{Li}$.

The blue curve in figure 1 is calculated for $\Gamma_{\text {supply }}=$ $10^{25} \mathrm{~m}^{-2} \mathrm{~s}^{-1}$, which corresponds to a Li flux that could be supplied purely passively via only capillary forces (as for the design proposed in [25]). The influence of $\Gamma_{\text {supply, }}$ surface layer thickness, $\epsilon_{\mathrm{cool}}, t$, and $R$ is visualized in figures 2 and 3 . Additionally, figure 2 shows the impact of doubling the thermal conductance of the system. 


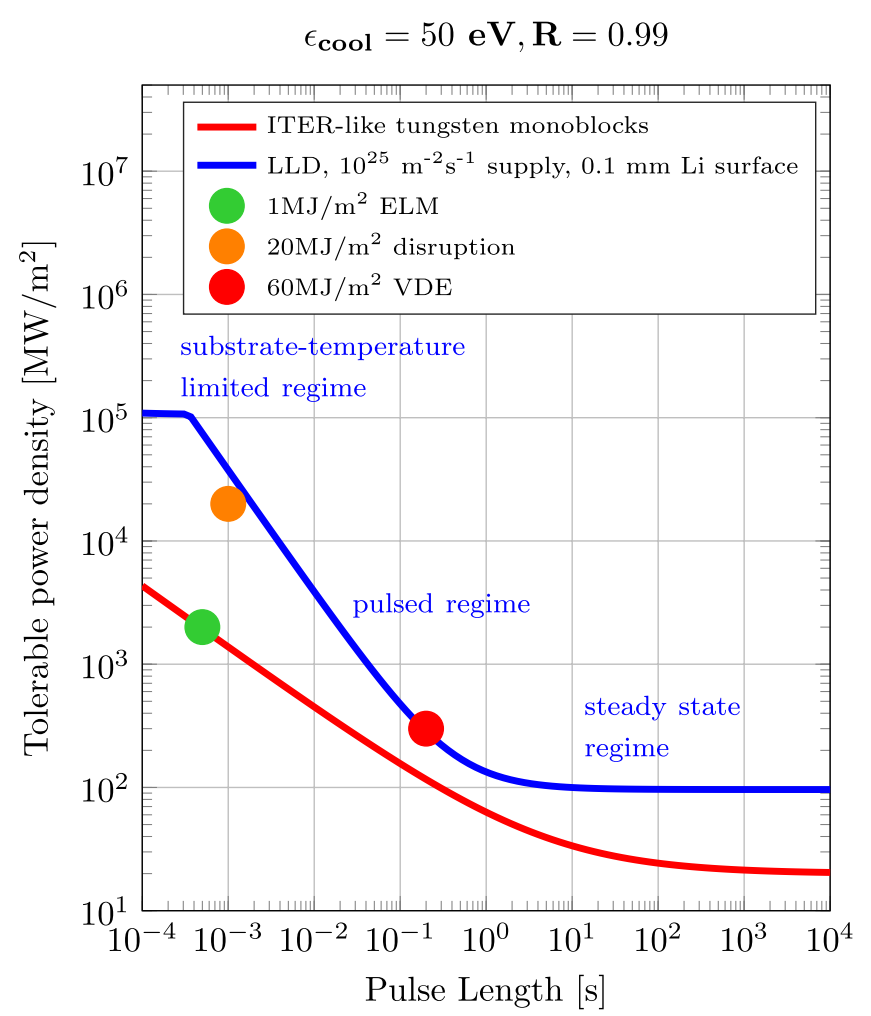

Figure 1. The maximum tolerable power density has been determined for a LL divertor target (blue) with thermal properties equal to the ITER-like monoblocks (red). This target has a Li supply rate $\Gamma_{\text {supply }}$ of $10^{25} \mathrm{~m}^{-2} \mathrm{~s}^{-1}$, and a $0.1 \mathrm{~mm}$ top layer. $\epsilon_{\text {cool }}$ and $R$ are taken $50 \mathrm{eV}$ and 0.99 , respectively. The blue curve shows three characteristic regimes: the steady state regime, the pulsed regime, and the substrate-temperature limited regime. The behavior of the former two regimes is detailed in figures 2 and 3 . The -1 slope of the pulsed regime is due to the fact that the thickness of the Li layer on the PFS corresponds to a fixed energy density which can be dissipated.

\section{Discussion}

In steady state (figure 2) two 'operating modes' can be distinguished clearly: a conductive and a Li dominated mode. At respectively low load, heat is dissipated mainly via conduction. In this mode, the tolerable power density can be even lower than for the monoblocks, as low surface temperature is required to maintain low net loss rates. Loads below $\sim 4 \mathrm{MW} \mathrm{m}^{-2}$ (depending on target conductance) are not possible because then the surface temperature becomes so low that retention becomes problematic. Increasing the effective thermal conductance of the system linearly increases the tolerable load as illustrated by the cyan curve.

In the Li dominated mode orders higher power density can be absorbed, though, this mode requires net Li loss rates at least above $10^{23} \mathrm{~m}^{-2} \mathrm{~s}^{-1}$. Note that in this mode, in order to handle the increased power density, only a slight increase in the surface temperature is required due to the strong dependence of evaporation on temperature. This results in a temperature locking phenomenon as recently observed for liquid tin [12], and earlier on carbon fiber composite [28]. Modeling in [15] also clearly demonstrated that the cause is the strong temperature dependence of the evaporation rate. For Li the

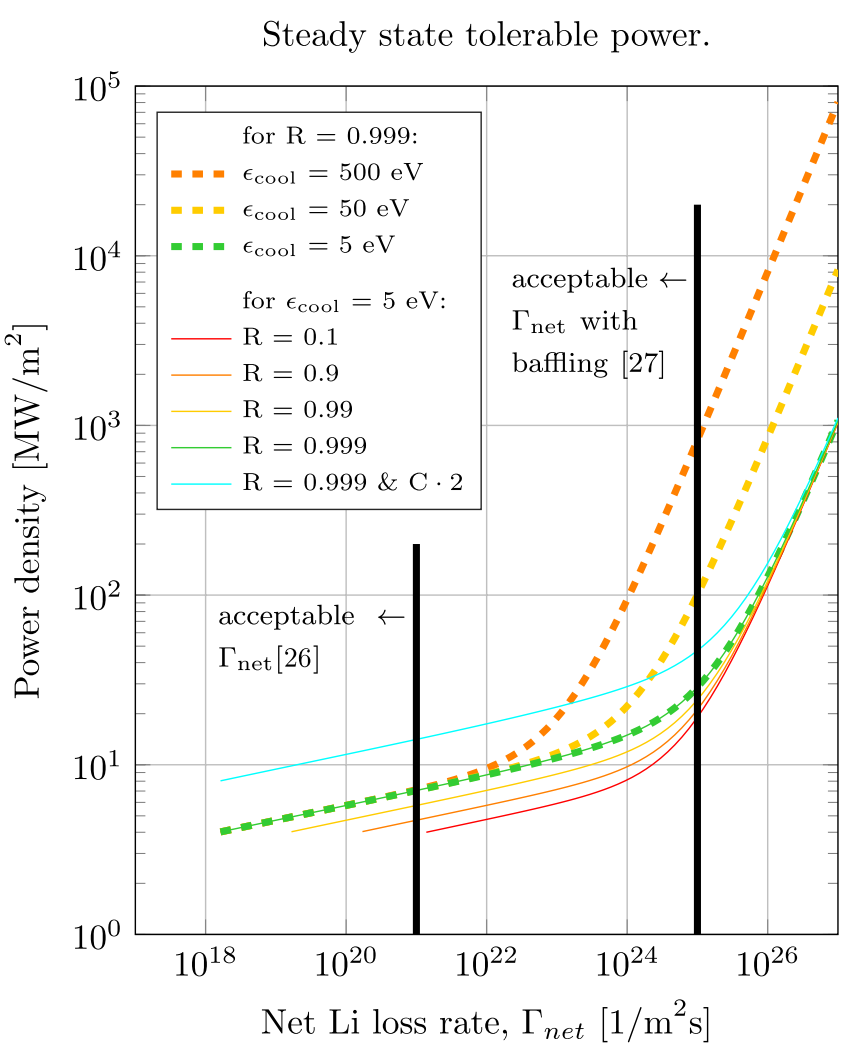

Figure 2. The steady state tolerable power density as function of $\Gamma_{\text {net }}$. A conductive regime and $\mathrm{Li}$ dissipation dominated regime can be observed below and above $\sim 20 \mathrm{MW} \mathrm{m}^{-2} \mathrm{~s}^{-1}$, respectively. Illustrated is also the influence of $\epsilon_{\text {cool }}$ (dashed), which mainly impacts the regime where dissipation via $\mathrm{Li}$ is dominant, and $R$ (solid), which impacts surface temperature to reach a given $\Gamma_{\text {net }}$ and thus the conductive dissipation. The cyan line illustrates the effect of increasing the target conductance with a factor of 2. Also note that fuel dilution in the core plasma limits the allowable $\Gamma_{\text {net }}$, illustrated by the black lines.

locking temperature is expected to be in the range of $800{ }^{\circ} \mathrm{C}-$ $1000{ }^{\circ} \mathrm{C}$.

The compatibility of these conditions with a high-performance fusion core needs to be assessed. It is estimated in [26] that $\Gamma_{\text {net }}$ should not exceed $\sim 10^{21} \mathrm{~m}^{-2} \mathrm{~s}^{-1}$ to avoid fuel dilution in the core (indicated by the left black line in figure 2). The acceptable flux density could be increased via strong baffling. For example, placing the target inside a vapor box as presented in [27] (despite being designed with a different working principle in mind) can reduce the Li outflow by four orders of magnitude, increasing the acceptable net loss rate up to $\sim 10^{25} \mathrm{~m}^{-2} \mathrm{~s}^{-1}$.

In the pulsed regime dissipation by the $\mathrm{Li}$ is dominant for layer thicknesses above $\sim 10$ micron, as indicated by the low dependence on pulse duration in figure 3. Consequently, the tolerable pulse energy density varies linearly with $\epsilon_{\text {cool }}$, until the layer reaches critical thickness where the temperature required to evaporate all $\mathrm{Li}$ during the pulse exceeds the substrate melting point. This point is clearly seen in figure 3 at a layer thickness around 300 micron, where the curves representing $1 \mathrm{~ms}$ pulses suddenly stop increasing. By increasing $R$ from 0.99 (used in figure 3) to 0.999 the critical thickness will be reduced from $\sim 300$ micron to $\sim 30$ micron. This is simply 
Tolerable pulse energy, $\mathrm{R}=0.99$

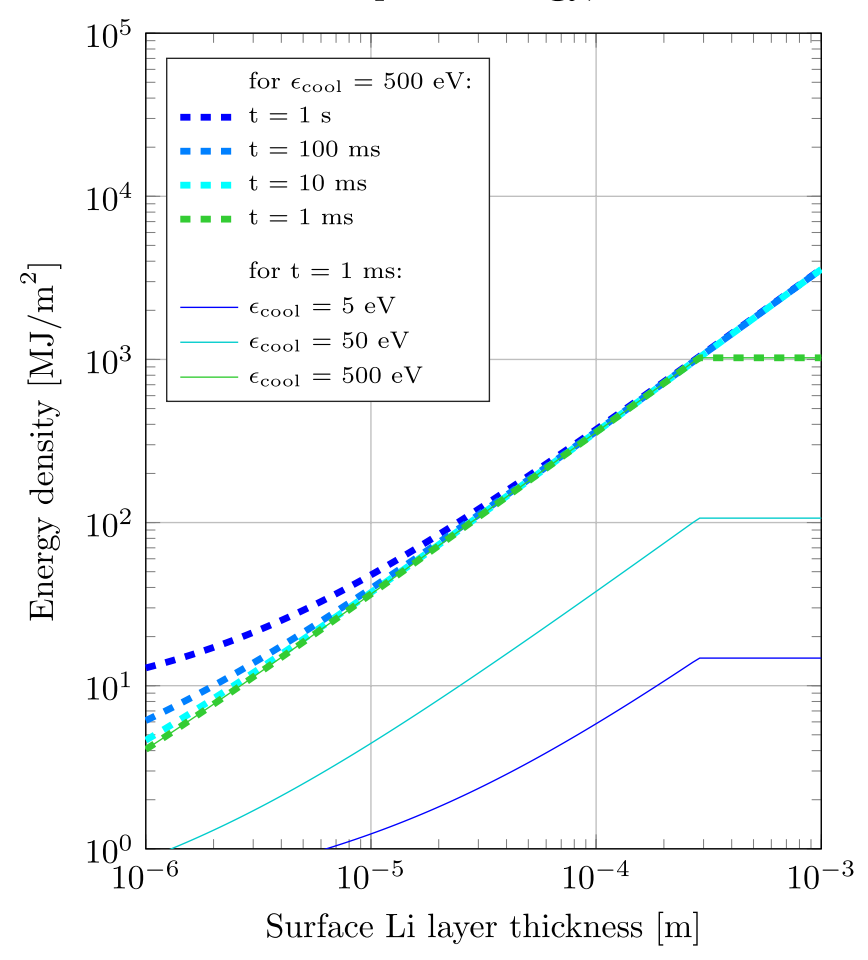

Figure 3. The energy density that can be dissipated in the pulsed regime depends linearly on the PFS LL layer thickness. For layers thinner than 10 micron conductive dissipation becomes important and dependence on pulse length $t$ increases. For high layer thickness the substrate temperature limit is reached before all $\mathrm{Li}$ can be evaporated (above 200 micron for $R=0.99$ as presented here).

because higher temperature is required to remove a given amount of $\mathrm{Li}$ when redeposition becomes stronger.

Now figure 3 can be used to find what layer thickness (horizontal axis) is needed to withstand arbitrary energy density ( $y$-axis). Most notable is that $1 \mathrm{~ms}$ disruptions of $20 \mathrm{MJ} \mathrm{m}^{-2}$, where it is expected that $\epsilon_{\mathrm{cool}}>50 \mathrm{eV}$, can already be withstood with layer thickness of 50 micron. Though not drawn in figure 3 the model also shows that for $200 \mathrm{~ms}$ vertical displacement events (VDE) up to $60 \mathrm{MJ} \mathrm{m}^{-2}$ a 50 micron layer is also sufficient if $\epsilon_{\mathrm{cool}}>150 \mathrm{eV}$. ELMs of $0.5 \mathrm{~ms}$ require even smaller layer thickness of $\sim 2$ micron when $\epsilon_{\text {cool }}>50 \mathrm{eV}$, corresponding to $\sim 10^{23} \mathrm{~m}^{-2} \mathrm{Li}$ particles being released into the plasma per ELM. Thus, there may still be concerns regarding the compatibility of high Li loss rates during ELMs with the core plasma. This is not problematic for VDEs and disruptions as the plasma is lost in these cases.

Lastly, the model considers a realistic range of $\epsilon_{\mathrm{cool}}, R$, and surface layer thickness, and therefore provides us with a limit to the power handing capabilities of a LL divertor target. Nevertheless, to obtain a more accurate estimate of power dissipation via $\mathrm{Li}$ further edge transport studies would be required. To also gain more insight into the acceptable Li loss rate, coupling edge and core transport modeling would even be required (for example continuing along the line of [29]).

\section{Conclusion}

Firstly, the formulated model can predict temperatures in LL divertor targets, making it a powerful engineering tool for the design of these components. Additionally, an important observation is the temperature locking effect, reducing both the peak temperature during steady state (to around $800{ }^{\circ} \mathrm{C}-$ $1000^{\circ} \mathrm{C}$ ) and during pulses. Namely, this will reduce thermal stresses, and therefore relaxes the high requirements to the strength of divertor substrate materials compared to conventional designs.

Secondly, the steady state tolerable load can be spectacularly increased compared to $\mathrm{W}$ monoblocks, but always at the cost of high LL loss rate. To match the monoblock performance loss rates are required of $\sim 10^{25} \mathrm{~m}^{-2} \mathrm{~s}^{-1}$ for $\epsilon_{\text {cool }}=5 \mathrm{eV}$ when $R=0.999$. Though, the loss rate for this case can be reduced $\sim 3$ orders of magnitude by increasing the thermal conductance of the system, and $\sim 4$ orders of magnitude via baffling as proposed in the vapor box concept [16]. This puts the net loss rate in the acceptable range. Nevertheless, the compatibility of specific loss rates with a high-performance fusion core should be further investigated.

Finally, regarding pulsed loads: Li layers with a thickness of 50 micron are already sufficient to withstand ELMs, disruptions, and VDEs. In the case of ELMs this may still lead to core plasma compatibility issues, but this is certainly not the case for the disruptions and VDEs as these are off-normal events, and thus the plasma is lost regardless. The ability to withstand these off-normal events is a significant and important improvement in robustness over traditional solid divertors.

\section{Acknowledgments}

This work has been carried out within the framework of the EUROfusion Consortium and has received funding from the Euratom research and training programme 2014-2018 under grant agreement No. 633053. The views and opinions expressed herein do not necessarily reflect those of the European Commission.

\section{ORCID iDs}

P. Rindt (1) https://orcid.org/0000-0003-3674-3191

T.W. Morgan (1) https://orcid.org/0000-0002-5066-015X

\section{References}

[1] Coenen J.W., De Temmerman G., Federici G., Philipps V., Sergienko G., Strohmayer G., Terra A., Unterberg B., Wegener T. and Van den Bekerom D.C.M. 2014 Liquid metals as alternative solution for the power exhaust of future fusion devices: status and perspective Phys. Scr. T 159014037 
[2] Ruzic D.N. et al 2011 Lithiummetal infused trenches (LiMIT) for heat removal in fusion devices Nucl. Fusion $\mathbf{5 1} 102002$

[3] Mirnov S.V., Azizov E.A., Evtikhin V.A., Lazarev V.B., Lyublinski I.E., Vertkov A.V. and Prokhorov D.Yu. 2006 Experiments with lithium limiter on T-11M tokamak and applications of the lithium capillary-pore system in future fusion reactor devices Plasma Phys. Control. Fusion 48 821-37

[4] Golubchikov L.G., Evtikhin V.A., Lyublinski I.E., Pistunovich V.I., Potapov I.N. and Chumanov A.N. 1996 Development of a liquid-metal fusion reactor divertor with a capillary-pore system $J$. Nucl. Mater. 233-7 667-72

[5] Jaworski M.A., Khodak A. and Kaita R. 2013 Liquid-metal plasma-facing component research on the National Spherical Torus Experiment Plasma Phys. Control. Fusion $\mathbf{5 5} 124040$

[6] Roth J. et al 2009 Recent analysis of key plasma wall interactions issues for ITER J. Nucl. Mater. 390-1 1-9

[7] Baldwin M.J., Doerner R.P., Luckhardt S.C. and Conn R.W. 2002 Deuterium retention in liquid lithium Nucl. Fusion 42 1318-23

[8] Taylor C.N., Luitjohan K.E., Heim B., Kollar L., Allain J.P., Skinner C.H., Kugel H.W., Kaita R., Roquemore A.L. and Maingi R. 2013 Surface chemistry analysis of lithium conditioned NSTX graphite tiles correlated to plasma performance Fusion Eng. Des. 88 3157-64

[9] Majeski R. et al 2004 Testing of liquid lithium limiters in CDX-U Fusion Eng. Des. 72 121-32

[10] Erents S.K. et al 1971 Trapping of keV deuterons in lithium J. Phys. D: Appl. Phys. 4305

[11] Gunn J.P. et al 2017 Surface heat loads on the ITER divertor vertical targets Nucl. Fusion 57046025

[12] van Eden G.G., Morgan T.W., Aussems D.U.B., van den Berg M.A., Bystrov K. and van de Sanden M.C.M. 2016 Self-regulated plasma heat flux mitigation due to liquid $\mathrm{Sn}$ vapor shielding Phys. Rev. Lett. 116135002

[13] Jung S., Andruczyk D. and Ruzic D.N. 2012 Laboratory investigation of vapor shielding for lithium-coated molybdenum in Devex IEEE Trans. Plasma Sci. 40 730-4

[14] Sestero A. 1977 Protection of walls from hard disruptions in large tokamaks Nucl. Fusion 17 115-23

[15] Skovorodin D.I., Pshenov A.A., Arakcheev A.S., Eksaeva E.A., Marenkov E.D. and Krasheninnikov S.I. 2016 Vapor shielding models and the energy absorbed by divertor targets during transient events Phys. Plasmas 23022501
[16] Goldston R.J., Hakim A., Hammett G.W., Jaworski M.A. and Schwartz J. 2017 Recent advances towards a lithium vapor box divertor Nucl. Mater. Energy 12 1118-21

[17] Kallenbach A. et al (The ASDEX Upgrade Team) 2013 Impurity seeding for tokamak power exhaust: from present devices via ITER to DEMO Plasma Phys. Control. Fusion 55124041

[18] Wischmeier M. 2015 High density operation for reactorrelevant power exhaust J. Nucl. Mater. 463 22-9

[19] Tskhakaya D., Jachmich S., Eich T. and Fundamenski W. 2011 Interpretation of divertor Langmuir probe measurements during the ELMs at JET $J$. Nucl. Mater. 415 S860-4

[20] Allain J.P. and Brooks J.N. 2011 Lithium surface-response modelling for the NSTX liquid lithium divertor $\mathrm{Nucl}$. Fusion $\mathbf{5 1} 023002$

[21] Abrams T. 2015 Erosion and re-deposition of lithium and Boron coatings under high-flux plasma bombardment $P h D$ Thesis Princeton University

[22] Pitts R.A. et al 2017 Physics conclusions in support of ITER W divertor monoblock shaping Nucl. Mater. Energy 12 60-74

[23] Jaworski M.A., Morley N.B. and Ruzic D.N. 2009 Thermocapillary and thermoelectric effects in liquid lithium plasma facing components J. Nucl. Mater. 390-1 1055-8

[24] Yu J.H., De Temmerman G., Doerner R.P., Pitts R.A. and van den Berg M.A. 2015 The effect of transient temporal pulse shape on surface temperature and tungsten damage $\mathrm{Nucl}$. Fusion 55093027

[25] Rindt P., Lopes Cardozo N.J., van Dommelen J.A.W., Kaita R. and Jaworski M.A. 2016 Conceptual design of a pre-loaded liquid lithium divertor target for NSTX-U Fusion Eng. Des. 112 204-12

[26] Morgan T.W., Rindt P., van Eden G.G., Kvon V., Jaworksi M.A. and Lopes Cardozo N.J. 2018 Liquid metals as a divertor plasma-facing material explored using the Pilot-PSI and Magnum-PSI linear devices Plasma Phys. Control. Fusion 60014025

[27] Goldston R.J., Myers R. and Schwartz J. 2016 The lithium vapor box divertor Phys. Scr. T 167014017

[28] Safronov V.M., Arkhipov N.I., Landman I.S., Pestchanyi S.E., Toporkov D.A. and Zhitlukhin A.M. 2009 Evaporation and vapor shielding of CFC targets exposed to plasma heat fluxes relevant to ITER ELMs J. Nucl. Mater. 386-8 744-6

[29] Poradziński M., Ivanova-Stanik I., Pełka G. and Zagórski R. 2017 Integrated core-SOL-divertor modelling for DEMO with tin divertor Fusion Eng. Des. 124 248-51 